\section{"I'm Not Trained for This!" And Other Barriers to Evidence-Based Social Skills Interventions for Elementary Students with High Functioning Autism in Inclusion}

\author{
Tracey Silveira-Zaldivara, Heidi Curtis ${ }^{b}$
}

\begin{tabular}{ll}
\hline Received: & 03 July 2019 \\
Revised: $\quad 20$ August 2019 \\
Accepted: $\quad 03$ September 2019 \\
ISSN: 1307-9298 \\
Copyright (C) IEJEE \\
www.iejee.com
\end{tabular}

DOI: $10.26822 /$ iejee.2019155337

\begin{abstract}
More students with High Functioning Autism (HFA) are in inclusive settings than ever before. The sheer physical combination of students with autism and their typical peers is insufficient to address the social deficits of students with autism. While evidence-based practices (EBPs) for social skills exist, these practices are not being implemented routinely in public schools. A mixed-methods study was conducted to identify barriers to the implementation of EBPs for social skills for students with HFA in early elementary inclusive settings. Thirty-three ( $n=33$ ) district inclusion related elementary school stakeholders completed a survey created to examine the barriers to the implementation of EBPs for social skills. Additional data collection methods included an open-ended survey question, focus groups ( $n=12$ of the 33 survey respondents), semi-structured interviews, and researcher field notes. Training, time, support, prioritization, materials, and staff mind-set were the top six barriers to the successful implementation of EBPs for social skills as identified by elementary inclusion stakeholders. These barriers revealed three key factors necessary to successfully implement EBPs for social skills: support, preparation, and motivation. The identification of barriers is the first step in bridging the gap between research and practice within inclusion school settings.
\end{abstract}

Keywords: Evidence-based practices (EBP), Social Skills, Barriers, High Functioning Autism (HFA), Inclusion,

\section{Introduction}

Over the past two decades, there has been a rapidly growing trend toward full inclusion settings for students with Autism (Snyder, De Bray, \& Dillow, 2016). In the United States, this is particularly true for students identified with high functioning autism, who now spend more time in public school regular education programs than ever before (Snyder et al., 2016). Students with higher functioning autism tend to be diagnosed later in life when increasing social demands noticeably compromise daily functioning, resulting in inimitable social and behavioural challenges in the school setting (Longtin, 2014; Rodríguez-Medina, Martín-Antón, Carbonero, \& Ovejero, 2016). Furthermore, students with high functioning autism may be unintentionally neglected -they may not receive the necessary services and supports that they need for later life success due to the tendency in schools to focus on academic deficits as opposed to social deficits (Spencer, 2013; Sullivan, 2009). Studies evaluating the success of inclusion for students with autism have illustrated that despite close proximity to typical peers, fewer than $5 \%$ of the student with autism's contacts with typical peers is related to friendship or social interaction (Hilton \& Liberty, 1992). In inclusive settings, typical peers tend to spend time interacting with other typical peers, while the student with autism continues to experience some level of isolation (Chamberlain, Kasari, \& Rotheram- Fuller, 2007; Fox, Hem-meter, Snyder, Binder, \& Clarke, 2011). If not properly implemented, inclusive settings may exacerbate social risks for the student with autism, such as the risks of bullying, peer rejection and stigma (Humphrey \& Symes, 2013; Kasari, Locke, Gulsrud, \& Rotheram-Fuller, 2012; Sreckovic, Brunsting, \& Able, 2014). Benefits to inclusion potentially consist of increased opportunities for social interaction, exposure to typical peer models for behaviour, and higher academic expectations (Odom, Buysse, \& Soukakou, 2012; Smith, 2012). However, multiple studies have demonstrated that many children with ASD do not benefit from inclusive learning without planning, instruction, and supports (Hansen, Blakely, Dolata, Raulston, \& Machalicek,2014; Koegel, Robinson, \& Koegel, 2009). Most students with HFA "will require supportive educational program throughout their academic tenure, despite their higher functioning abilities." (Sansosti \& Sansosti, 2012, p. 917). Hansen et al., (2014) conducted a literature review of multiple single-case design research studies; the researchers noted that more than any other support, children with autism in inclusive settings need access to evidence-based practices for social skills to be successful.

\section{Deficits in Social Skills Impact Many Life Domains.}

Students with autism exhibit many social challenges, including a lack of empathy, social communication struggles, difficulties in joint attention, and impairment in routine interaction such as cooperation, helping, and sharing (Grove, Baillie, Allison, Baron-Cohen, \& Hoekstra, 2014; Miller et al., 2015). The frequency, intensity, and comprehensive nature of the social deficits of individuals with autism can have significant impact on many life domains. Social deficits impact academic achievement, classroom behaviour, relationships, mental health, and life outcomes (Cook, Ogden, \& Winstone, 2017; Hillier, Fish, Siegel, \& Beversdorf, 2011; Lauderdale-Litten, Howell, \& Blacher, 2013). Social skills have a greater impact on the quality of life for individuals with high functioning autism than do any specific diagnoses and/or cognitive advantage (Mordre et al., 2012). Therefore, implementing appropriate evidence-based strategies for social intervention early and continuing those interventions throughout one's educational tenure, is the most optimal approach to meeting the social needs of students with autism (Hansen et al., 2014; Starr, Popovic, \& McCall, 2016).

Deficits in Social Skills Related to Academic Achievement

Deficits in social skills have been linked to certain academic deficits for some children with autism (Davidson \& Weis-

\footnotetext{
a Corresponding author: Tracey Silveira-Zaldivar, Northwest Nazarene University, 623 S. University Blvd., Nampa, Idaho, 83686 USA. 
mer,2014; Rabiner, Godwin, \& Kenneth, 2016). For example, while students with autism may do well with reading decoding, many struggle with reading comprehension (Ricketts, Jones, Happé, \& Charman, 2012). Reading comprehension challenges of students with autism may be directly related to the social nuances required in reading comprehension (Åsberg, Kopp, Berg-Kelly, \& Gillberg, 2010; Ricketts et al., 2012). Furthermore, researchers have cited a correlation between a lack of social ability and difficulty in acquiring alphabet knowledge for preschool students with autism (Davidson \& Weismer, 2014).

\section{Deficits in Social Skills Related to Externalized Behaviour} Children with ASD often exhibit maladaptive externalized behaviours at rates significantly higher than their typical peers. These maladaptive behaviours may include aggression, compulsions, tantrums, eloping (leaving a designated area without permission), self-injury, and impulsivity, as well as other destructive behaviours (Eisenhower, Baker, \& Blacher, 2005; Øien \& Eisemann, 2015). Nearly one third of children with autism exhibit severe aggressive behaviours in a variety of settings (Dominick et al., 2007). Shea, Payne, and Russo (2018) demonstrated an empirical link between social deficits and externalized behaviour. Shea et al. (2018) determined that socialization accounted for $50 \%$ of the variance in externalized behaviours for children with ASD, but not for children with typical development. Even children with autism as young as 3 years of age demonstrate more frequent and more severe internalizing and externalizing behaviours than typical peers or children with intellectual disability (Eikeseth, Klintwall, Jahr, \& Karlsson, 2012). Research has established a firm relationship between maladaptive behaviours and deficits in communication and social skills; underscoring the need for intervention strategies that target these primary deficits (Fulton, Eapen, Črnčec, Walter, \& Rogers, 2014; Vismara \& Rogers, 2010).

Disruptive behaviour in school (perceived or actual) often results in an increase in office referrals and suspensions (Mallett, 2015). Increased suspensions have been associated with adverse student outcomes in academic achievement and graduation rates as well as adverse life outcomes (Balfanz, Byrnes, \& Fox, 2015; Wolf \& Kupchik, 2017). When disruptive behaviours are reduced, there is a greater likelihood of enhanced learning, independence, and improved social relations (Fulton et al., 2014). Maladaptive behaviours are the most commonly cited barrier to the inclusion of children with ASD in regular education settings (Brown \& Mclntosh, 2012; Fulton, et al., 2014). The severity of a student's destructive behaviours and social functioning is a deciding factor in the placement of students with autism in non-public schools as opposed to maintaining students in the public school and/or the least restrictive environment (Lauderdale-Litten et al., 2013). Such findings suggest that targeting the improvement of social skills for students with HFA may significantly curtail maladaptive behaviour and increase the likelihood of the student's success.

\section{Deficits in Social Skills Impact Relationships}

Social skill deficits impede social relationships in the school, home, and community setting. Children with ASD tend to report: (a) fewer friendships, (b) poorer friendship quality, (c) reduced appropriate social interaction during non-structured periods (such as lunch or recess at school), and (d) higher incidents of bullying (Calder, Hill, \& Pellicano, 2013; Humphrey \& Symes, 2011; Kasari et al., 2011; Mazurek, Kanne, \& Wodka, 2014). Some studies have made direct links between the social skill deficits of the individual with autism and the frequency and severity of the bullying that they have endured (Goodall, 2015; Northern Ireland Schools for Autism and Related Conditions [NISARC] Survey, 2015). Observations of kindergarten and elementary school students with autism during recess periods indicate that children with autism engage primarily in solitary play, lack symbolic play, and/or engage in fewer interactions with typical peers, even in inclusive settings (Fink, Begeer, Peterson, Slaughter, \& Rosnay, 2014; Kamps et al., 2015). On average, students with autism spend $30 \%$ of recess time alone, while typical peers spend $9 \%$ of recess alone (Locke et al., 2016). One 5-year-old child reported, "School is the loneliest place on earth" (Zeedyk, Cohen, Eisenhower, \& Blacher, 2016, p. 446). Zeekyk et al., (2016) conducted a comprehensive mixed methods study to evaluate friendship, loneliness, and self-competence in over 120 young HFA students ages 4 to 7 and nearly $40 \%$ reported difficulties making friends at school and at least $25 \%$ reported feeling lonely and left out in school. Cook et al. (2017) found that several adolescent girls try to conceal their autism characteristics to make friends. Teacher-student conflicts were found to exacerbate feelings of loneliness in students with HFA (Zeedyk et al., 2016). According to Zeedyk et al. (2016): "Teachers may not be aware of the degree to which their behaviours and attitudes toward children with ASD impact both what the child with ASD thinks about him/herself, and possibly how peers view him/her" (p. 446).

\section{Social Deficits and Co-Morbidity - The Impact on Mental} Health

Individuals with autism often present with comorbid mental health concerns ranging from anxiety, to depression, to ADHD, to mood disorders, and conduct disorders among others (Chiang \& Gau, 2016; Ratcliffe, Wong, Dossetor, \& Hayes, 2015). Researchers postulate that the quality and frequency of social interaction and communication with others is directly linked to levels of loneliness and anxiety (Bauminger \& Kasari, 2000; Mazurek et al., 2013). Santomauro, Sheffield, and Sofronoff, (2016) found that difficulties with social emotional regulation (controlling one's emotions) often continued through young adulthood.

\section{Social Deficits and Life Outcomes}

The long-term effect of deficits in social competence can be profound. Jones, Greenberg, and Cowley (2015) reviewed teacher assessments of the social competence of nearly 1,000 kindergarten students and followed them from between 13 to 19 years later to assess the impact of social competency on multiple measures. The results showed statistically significant associations between kindergarten social skills and young adult outcomes in (a) employment, (b) higher education, (c) criminality, (d) chemical dependency, and (e) mental health. An overwhelming 50\% of young adults with autism (ages 19-23) have not held a job or attended postgraduate education within two years of leaving high school (Shattuck et al., 2012). Furthermore, adults with autism experience greater levels of anxiety and depression (Hillier et al., 2011; Van Steensel, Deutschman, \& Bogels, 2012), and they are more dependent upon government assistance than typical peers (Mordre et al., 2012). Despite common perception, higher intelligence does not necessarily correlate with greater social strengths (Kasari et al., 2011; Mordre et al., 2012). Given two individuals with autism of at least average to above average cognition, studies have found that the individual who is most likely to succeed in life is the individual with greater social skills (Mordre et al., 2012). Mordre et al. (2012) followed over 110 children with some form of autism from childhood to adulthood. The only difference between those individuals perceived with a more severe form of autism compared to a milder form of autism (per DSM-IV criteria), was that the students with a milder form of autism received slightly lower rates of disability income. The study by Mordre et al. (2012) revealed that pro-social functioning was the single distinguishing criterion amongst the two groups with higher social skills corresponding to lower levels of disability income. 
Evidence-Based Practices for Social Skills

A literature review of multiple single-case design research studies by Hansen et al. (2014) revealed that more than any other support, children with autism in inclusive settings need access to evidence-based practices for social skills to be successful. There are varying descriptions of what constitutes an evidence- based practice, although most agree that an evidence-based practice is a practice that has been demonstrated to engender a favourable result via research (Cook \& Odom, 2013; McGrew, Ruble, Smith, 2016). According to the National Professional Development Council on Autism (Wong et al., 2015) an evidence-based practice is defined via any of the following criteria: (a) two or more high quality experimental or quasi experimental design research studies by at least two or more research groups; (b) five or more single case-designs by at least three different researchers; or (c) one high quality experimental design study accompanied by three high quality single case design studies (McGrew, Ruble, \& Smith, 2016). The National Professional Development Council has identified the following key evidence-based practices for social skills: (a) peer mediated interventions (PMI), (b) social narratives (most optimally used as a supplemental program or for a particular skill), (c) social skills training (SST), (d) structured play group (SPG), (e) Pivotal Response Training $(P R T)$, and ( $f$ ) video modeling. Positive behavioural reinforcement interventions, specifically, the utilization of applied behaviour analysis techniques are also considered as an appropriate evidence-based intervention to enhance social skills (Gerhardt \& Crimmins, 2013; National Autism Center, 2015). Positive behaviour reinforcement interventions are the most-commonly used strategy for reducing maladaptive behaviours and increasing appropriate behaviours. Adding positive behaviour interventions to other evidence-based social skills interventions such as peer mediated interventions and video modeling, can increase the efficacy of those programs (Camargo et al., 2014). In a variety of studies reviewed, the strategies incorporated in PMI of modelling, prompting, and reinforcement are considered the most effective procedures for teaching social skills (Cole \& McCurdy, 2014; Kamps et al., 2015). Along with PMI, video modeling has been gaining momentum in the field of social skills intervention. Video modeling is particularly effective for teaching novel social behaviour (Plavnick, Kaid, \& MacFarland, 2015).

Challenges to the Implementation of Evidence-Based Practices While many evidence-based practices have been identified to enhance the social functioning of individuals with autism, research has indicated that few public schools successfully utilize and/or implement evidence-based interventions for autism (Locke et al., 2016; Owens et al., 2014; Stahmer et al., 2015). Less than $10 \%$ of school-based interventions for students with autism are evidence-based (Hess, Morrier, Hefflin, \& Ivey, 2008). A recent survey administered to 32 elementary inclusion staff members revealed that the inclusion staff were largely unfamiliar with EBPs for social skills for students with autism (Silveira-Zaldivar, 2019). Even personnel expected to have knowledge of evidenced based practices, such as school psychologists and counselors, lack competent knowledge and training of EBPs (Combes, Chang, Austin, \& Hayes, 2016; Hicks, Shahidullah, Carlson, \& Palejwala, 2014). Nearly $60 \%$ of school psychologists reported not having any training in conducting and implementing social skills training for students with autism in their graduate programs (Combes et al., 2016). Regular education inclusion teachers, especially, have voiced concerns regarding the lack of training that they have received to meet the needs of students with autism in their classrooms (Stahmer et al., 2015; Strong, 2014). Lindsay, Proulx, Thomson, and Scott (2013) noted that teachers feel unprepared to support students with autism "socially, academically, and behaviourally" (p. 348). There is a critical lack of guidelines and training in teacher programs regarding the implementation of EBPs for autism (Lauderdale-Litten \& Brennan, 2018; Scheeler, Budin, \& Markelz, 2016). School staff have also reported that they do not have adequate support staff to facilitate EBPs for students (Able, Sreckovic, Schultz, Garwood, \& Sherman, 2015; Locke et al., 2015). The lack of educator practice guidelines and training in teacher programs have contributed to the lack of implementation of appropriate interventions (Lauderdale-Litten \& Brennan, 2018; Marder \& Fraser, 2012). Regular education teachers have been singled out as the inclusion educators most likely to experience burnout (Boujut, Dean, Grouselle, \& Cappe, 2016), most likely in need of training (Lauderdale-Litten \& Brennan, 2018) and, yet, potentially, the most critical to fostering the student's sense of belonging (Zeedyk et al., 2016). Public schools face a multitude of challenges in implementing appropriate evidence-based interventions such as: lack of funding, lack of knowledge, lack of training, lack of support, and lack of time (Grindle et al., 2009; Miller, 2017; Owens et al., 2014). Therefore, when educators attempt to implement evidence-based interventions, they often do so without fidelity and/or consistency; or they avoid evidence-based practices altogether and cling to comfortable, non-established interventions (Owens et al., 2014; Stahmer et al., 2015). Even when provided with support and training, interventions in the schools can still be lacking (Cidav, Marcus, \& Mandell, 2012). A dearth of research within the public- school system further contributes to the gap between research and practice (Jordan, Roberts \& Hume, 2019). While there have been some research studies focusing on identifying the barriers to the successful implementation of EBPs for social skills, few studies have involved mixed methods or participatory action research methods. The use of mixed methods and the involvement of stakeholders allowed for a rich and deep understanding of the barriers to successful implementation of EBPs within a particular setting, such as the inclusive classroom environment.

Due to the dramatic increase of children with autism and the impact of social skill deficits on many life domains, the need for intervention is critical (Locke et al., 2016; Marder \& de Bettencourt, 2015). Applying appropriate evidence-based strategies for social intervention early and continuing those interventions throughout one's educational tenure, is optimal (Hansen et al., 2014; Starr, Popovic, \& McCall, 2016; Wong et al. 2015). The barriers to the implementation of EBPs in schools are multifaceted and include several organizational and individual factors (Domitrovich et al., 2008; Locke et al., 2016). Understanding the barriers to implementing EBPs in schools is key to creating strategies to overcome the barriers (Kasari \& Smith, 2013; Locke et al., 2016).

\section{The Purpose of the Study}

The intent of this study is to identify the barriers to the implementation of EBPs for social skills for students with HFA in an inclusive setting. The research presented is derived from a broader study utilizing participatory action research (PAR) and mixed-methods in a public-school district to bridge the gap between research and the practice of evidence-based strategies for social skills for students with HFA in inclusive settings. In PAR research, the researcher assumes an active and often intimate role in the research process (Stringer, 2014). The broader PAR study involved additional surveys and interviews, focus groups, training inclusion stakeholders in EBPs for social skills following completion of the initial surveys, and the implementation of evidence practices for social skills for students with HFA in inclusive settings. The broader study transpired over a three-month period in the fall of the 2018 to 2019 school year. While a variety of barriers to the implementation of EBPs have been documented in research, the primary researcher desired to explore the opinions and beliefs of the inclusion personnel in the district where the primary researcher practices - as those opinions would be most important when attempting to create a plan to implement EBPs routinely and with fidelity in that particular school district. If other school systems or school districts were to undertake a similar strategy, they might be more successful in implementing sustainable plans to implement EBPs within 
their own school environments.

\section{Methodology}

This study utilized a mixed- methods design to explore barriers to implementation of EBPs for social skills for students with autism in inclusive settings. This study addressed the following research questions:

1. What are some of the reported barriers (if any) that a school district encounters when implementing evidence-based practices for social skills interventions for elementary school students with HFA in the inclusive setting?

2. What are some of the needs and desires of public- school stakeholders regarding social skills interventions for students with HFA that will facilitate the successful implementation of evidence-based practices in elementary school inclusive settings?

This study was approved by the Northwest Nazarene University Institutional Review Board.

Combining qualitative and quantitative measures is a method of data triangulation that impacts the overall validity of a study. Quantitative measures tend to lend credibility to a study while qualitative measures, such as interviews provide a humanistic perspective that cannot be replicated via other types of design. Semi-structured focus group methods allow for participants to interact and respond to one another following key questions posed by the researcher (Harrell, \& Bradley, 2009). Involving site stakeholders in processes such as structured interviews and focus groups facilitates a rich insight into stakeholder perspectives regarding community issues of concern. Participatory research is predicated upon the willingness of research participants to share their personal views of a situation without fear of reproach. Participatory research thus provides a safe place for participants to share concerns and opinions (Kemmis, 2016; Stringer, 2014). The freedom to dissent is central to the success of participatory action research as it promotes understanding.

The setting was a large public urban district in a southwestern state, which encompassed a range of economic and ethnic diversity. With over 27,000 students, the district is a large and ethnically diverse school district comprised of families representing a wide socio-economic status range. At least half of the students qualify for free or reduced lunch. Furthermore, nearly half of students are identified as Hispanic, although staff members are predominately Caucasian. The premise of the district's formal inclusion program (comprised of grades K-3 at the time of the study) was to have the majority of the district's students with special needs attend regular education settings in which the regular education teacher serves as the primary educator of the student. Special education teachers and other district support personnel assume supportive roles in this district's inclusion model.

\section{Participants}

Purposeful sampling was used to identify and recruit participants. Stratified purposeful sampling is a sampling technique in which the "Purposeful Sampling frame is divided into strata to obtain relatively homogeneous subgroups and a purposeful sample is selected from each stratum" (Onwuegbuzie \& Collins, 2007, p. 286). Researchers are often encouraged to choose a research population or a participant who will demonstrate an understanding of the research problem or issue (Creswell, 2012; Marshall \& Rossman, 2016). The participants invited to participate in the study were related in some form to the district's early elementary inclusion program, either in roles of service providers, parents of students with HFA, support staff, educators, or leadership roles. Permission for involvement in the study was obtained from the district superinten- dent as well as individual school site principals following district protocol. Once permission to contact inclusion related stakeholders had been obtained from the school site administrator, the researcher sent out an electronic invitation to participate in the study. The response rate for survey completion only (without participating in any other aspects of the study) was $56 \%$ of those individuals approached to participate (18 of 32 individuals). A response rate of over $50 \%$ is considered more than sufficient for educational surveys (Richardson, 2005). Studies have shown that response rates with lower rates (even as low as 5\%) are sufficient to generate accurate results, especially if the sample is considered representative of the general population of interest in the research study (Holbrook, Krosnick, \& Pfent, 2010). All study participants signed written consent forms to participate in the study. Token incentives (a gift card for coffee) were provided to study participants.

A total of $33(n=33)$ different district inclusion related stakeholders participated in the barriers portion of the study including 32 ( $n=32$ ) public school educators related to the district inclusion program and one parent $(n=1)$ of a child with HFA placed in a district inclusive setting. Thirty-two public school employees completed the survey regarding barriers to EBPs involved in the study. Of the 32 employees who completed the surveys, 13 of them volunteered to participate in either a semi-structured focus group ( $n=11$ ) or a personal semi-structured interview $(n=2)$. The parent of the child with HFA in an inclusive setting also attended the focus group and completed the survey addressing potential barriers to the implementation for EBPs. Thus, the total number of participants in the focus group was 12. (Four parents had been invited to participate in the focus group via electronic notice and flier based on purposeful sampling and meeting study criteria -having a child with HFA in an inclusive setting in the district-, but only one was able to attend the actual group). The following inclusion stakeholders participated in this study: (a) School Psychologists ( $n=7)$, (b) Regular Education Teachers $(n=8)$, (c) Special Education Teachers $(n=8)$, (d) school Behaviour Staff (consisting of para-professionals and their two supervisors) ( $n=7)$, (e) Speech Therapists $(n=2)$ and $(f)$ one Parent of a Child with HFA.

Of the 33 total participants, twenty-five study participants $(n=25)$ identified themselves as predominately Caucasian $(76 \%)$. Five participants $(n=5)$ identified themselves as Hispanic (15\%). Two participants $(n=2)$ identified themselves as Asian (6\%), and one declined to state (3\%). Only one male staff member participated in the study. The median age of participants was 40-50. Staff years of experience ranged from five years to 29 years. Fifty-nine percent of the school staff participants had over ten years of education experience. Study participants reported a wide range of preparation in autism ranged from no training at all to college level courses.

The focus group members $(n=12)$ represented the following diverse stakeholder district roles: (a) School Psychologists $(n=2)$, (b) Special Education Teachers $(n=3),(\mathrm{d})$ Behaviour Staff $(n=5)$, (e) a Speech Therapists $(n=1)$. and (f) a Parent of a Child with HFA $(n=1)$. The two staff who were not able to attend the focus group, but were willing to be interviewed, consisted of the following: regular education teachers $(n=2)$. Pseudonyms and number codes were utilized to protect confidentiality of all participants.

\section{Quantitative Measure: A Survey}

Questions for the survey were modified by the first author from already existing questionnaires where applicable and additional items were added based on expert opinion. Survey questions were then vetted by two additional experts in the field of education and autism. The survey addressed any potential barriers for the implementation 
of EBPs. In addition to the Likert Scale Survey, the following open-ended question was included on the survey form: Please comment on any additional barrier that you see to implementing direct social skills training in the inclusive school setting.

\section{Procedures}

Following written permission to participate in the study, the inclusion related school staff were sent the survey electronically. The survey was brief and easy to complete, requiring less than 20 minutes of the staff member's time. The completed surveys were then left at various respective elementary schools in designated envelopes. Confidentiality of all survey participants was maintained via numbered coding. Following completion of the surveys, 12 inclusion related staff stakeholders (11 staff members and the parent of a child with HFA) agreed to participate in semi-structured focus groups. The focus group participants completed the survey upon arrival to the initial focus group. An additional two staff members expressed a willingness to be interviewed, but they were not able to participate in the scheduled focus groups. Therefore, those two staff members were interviewed separately via a semi-structured interview and posed the same questions as the focus group participants. All the survey forms were completed prior to the actual start of the focus group and the administration of the semi-structured interviews.

Each focus group lasted 120 minutes, was audio-recorded, and conducted in English in a room at the district office. At the first group, the researcher subsequently invited all focus group members to introduce themselves to the group and then the researcher presented several a priori questions:

1.What are some of the evidence-based social skills interventions for elementary students with autism that you are aware of?

2.In your opinion, what are some of the evidence-based social skills interventions currently being implemented by our district for students with High Functioning Autism for students in the inclusive setting?

3. What are some of the barriers (if any) to implementing evidence based social skills program that you have encountered?

4. What do you need (or what does the district need) in order to implement evidence based social skills training for students with high functioning autism on a regular and consistent basis?

The remainder of the focus groups was devoted to a presentation by the primary researcher on the impact of social skills on the following areas: behaviour, academic achievement, mental health, relationships, and adult outcomes. Group ethics and the study overview were addressed during the first group. The primary researcher allowed time for questions throughout the session and recorded field notes. For the additional two staff members who were not able to attend the focus group meeting, their semi-structured interviewed were conducted individually via a face-face format with the primary researcher. Each interview lasted approximately 20 minutes.

\section{Data Collection}

This mixed-methods design study incorporated several data collection methods including the survey, focus groups with guided interview questions, an open- ended question on the survey, semi-structured interviews, and the researcher field notes during discussions. Triangulation of sources and methods can provide a deeper understanding of a phenomenon being studied (Patton, 1999).

\section{Quantitative Analysis}

A Cronbach's alpha analysis was conducted to validate the internal reliability of the survey addressing potential barriers. The results of the Cronbach's alpha indicated acceptable reliability $(a=0.87)$. All items on the scale appeared to be worthy of retention, resulting in a decrease in alpha if deleted. Descriptive analysis via the SPSS software program was performed on the responses to the survey. The descriptive analysis included frequency, mode, mean, median, percentages, and standard deviation. An Analysis of Variance Assessment (ANOVAS) was completed to compare the results of the two respective surveys based on an inclusion staff member's job title (role) in the district.

\section{Qualitative Analysis}

The data from all direct semi-structured interviews and the focus groups were transcribed verbatim by a contracted transcriptionist who signed a confidentiality agreement. Member checking was employed to verify accuracy of information heard by the primary researcher. Essential field notes and the responses to the open-ended question in writing were transcribed to typed form as well. Once data from the various qualitative resources were accumulated, the data were entered collectively into the NVivo assistance software program. The N-Vivo software assisted the primary researcher to conduct a modified grounded theory analysis (theory is derived from data and supported by distinct examples) of all of the qualitative data. The researcher took the following steps to analyze the qualitative data utilizing NVivo:

- The researcher imported the relevant qualitative data into the NVivo software program.

- The researcher then opened up the explore category and read all of the responses - creating corresponding nodes and/or codes.

- Once nodes were determined, the primary researcher utilized two different types of queries to obtain frequency data and to provide supporting examples of text for each theme area (one-word searches as well as text searches). The primary researcher allowed for synonyms of the words in the query. The program populated the frequency for all hits via texts and/or words. The primary researcher then re-read the sections and confirmed appropriateness of the various themes. Supporting content and/or text was then dragged and dropped to the appropriate node, tabulating frequency entries. dragged the theme content and/or test to the appropriate node and the program tabulated the frequencies of the entries.

- The primary researcher created visual representations to display the data.

- The primary researcher provided narrative analysis of the results.

Categories tended to emerge via an analysis of data and these categories were then linked together and synthesized to provide a more focused analysis of the data (Basit, 2003).

\section{Results}

Quantitative Analysis of the Survey Addressing Potential Barriers to Evidence-Based Practices

The following table 1 provides descriptive statistics for each of the barrier domains as rated by the survey participants. 
Table 1. Potential Barriers Survey Statistical Analysis Results

\begin{tabular}{|c|c|c|c|c|c|c|c|}
\hline $\begin{array}{l}\text { Potential } \\
\text { Barrier }\end{array}$ & $\begin{array}{l}\text { Lack of } \\
\text { Training } \\
\text { in EBPs }\end{array}$ & $\begin{array}{l}\text { Lack of } \\
\text { Staff }\end{array}$ & $\begin{array}{l}\text { Lack of } \\
\text { Materials }\end{array}$ & $\begin{array}{l}\text { Prioritization of Needs/ } \\
\text { Demands in the School Day (i.e. } \\
\text { emphasis on academics) }\end{array}$ & $\begin{array}{l}\text { Lack of Time to } \\
\text { Implement Social } \\
\text { Skills Interventions }\end{array}$ & $\begin{array}{l}\text { Cost of } \\
\text { Implementation }\end{array}$ & $\begin{array}{l}\text { Administra- } \\
\text { tive Support }\end{array}$ \\
\hline N (valid) & 33 & 33 & 33 & 33 & 33 & 33 & 33 \\
\hline Mean & 2.73 & 2.67 & 2.48 & 2.61 & 2.54 & 2.18 & 2.10 \\
\hline Median & 3.0 & 3.0 & 3.0 & 3.0 & 3.0 & 2.0 & 2.0 \\
\hline
\end{tabular}

Thirty-three school $(n=33)$ inclusion elementary stakeholders (32 staff members and one parent of a student with HFA) completed the survey. The most significant barrier as noted by the mean for all participants was "lack of training" ( $M=2.73)$. The barriers of greatest concern based solely on the mean score for all participants (focusing on $M>2.5, M d n=3.0$ ) are as follows: lack of training, lack of staff, prioritization concerns, and lack of time. All the potential barriers received overall average ratings of at least "somewhat of a barrier." Table 2 provides a detailed summary of the frequency and corresponding percent of responses corresponding to each potential designated barrier in the survey completed by district personnel (the parent responses were excluded from the following table to allow for a direct focus on school inclusion staff practices).

Table 2. Barriers to EBP Survey - Frequency and Percent of Responses

\begin{tabular}{|c|c|c|c|c|c|c|c|}
\hline \multirow{2}{*}{$\begin{array}{l}\text { Domain Area } \\
\text { Lack of } \\
\text { Training }\end{array}$} & \multirow{2}{*}{$\begin{array}{l}\text { Sample } \\
\text { Size } \\
\text { Valid } \\
(n)\end{array}$} & \multicolumn{2}{|c|}{$\begin{array}{l}\text { Not a Barrier } \\
\text { Frequency/ } \\
\text { Percent }\end{array}$} & \multicolumn{2}{|c|}{$\begin{array}{l}\text { Somewhat } \\
\text { of a Barrier } \\
\text { Frequency/ } \\
\text { Percent }\end{array}$} & \multicolumn{2}{|c|}{$\begin{array}{l}\text { Significant } \\
\text { Barrier } \\
\text { Frequency/ } \\
\text { Percent }\end{array}$} \\
\hline & & 0 & 0 & 11 & $34.3 \%$ & 21 & $65.6 \%$ \\
\hline Lack of Staff & 32 & 0 & 0 & 13 & $40.6 \%$ & 19 & $57.6 \%$ \\
\hline Prioritization & 32 & 0 & 0 & 15 & $46.9 \%$ & 17 & $53.1 \%$ \\
\hline Lack of Time & 32 & 2 & $6.2 \%$ & 13 & $40.6 \%$ & 17 & $53.1 \%$ \\
\hline $\begin{array}{l}\text { Lack of } \\
\text { Materials }\end{array}$ & 32 & 1 & $3.1 \%$ & 17 & $53.1 \%$ & 14 & $43.8 \%$ \\
\hline $\begin{array}{l}\text { Administra- } \\
\text { tive Support }\end{array}$ & 32 & 10 & $31.2 \%$ & 12 & $37.5 \%$ & 10 & $31.2 \%$ \\
\hline Cost & 32 & 4 & $12.5 \%$ & 21 & $65.7 \%$ & 7 & $21.9 \%$ \\
\hline
\end{tabular}

All the barriers received overall average ratings of at least "somewhat of a barrier." To determine if a staff member's district job title (i.e. district role) had a significant impact on one's responses to the survey, the researcher conducted an ANOVA. There were no significant differences between group means based on district job title on the survey, suggesting a unity in voice regarding the perceived barriers to the implementation of EBPs for social skills for students with HFA in inclusive settings.

Qualitative and Combined Qualitative and Quantitative Analysis of Results

In addition to the survey questions, the primary researcher posed the following open-ended comment to participants on the Barrier's to EBPs survey form, designed to elicit responses not addressed and/or that might have been missed on the actual survey: Please comment on any additional barriers that you see to implementing direct social skills training in the inclusive school settings. Eight survey respondents wrote responses to this question. Of the eight respondents, three staff reported concerns about lack of buy-in from staff. One participant wrote, "There is lack of willingness of general education teachers to want to be trained and to implement programs." Participants expressed a concern that general education teachers (also known as regular education teachers) were involved in inclusion as a result of a mandate, as opposed to being internally motivated. Three others expressed a concern about the lack of support staff and lack of collaboration opportunities with other staff members, especially those with expertise in the area. Other participants reiterated the lack of training that they had received to successfully implement strategies that students with autism need. At least one participant suggested that training should not be offered just to teachers, but to all staff who work with students throughout the day, such as recess supervisors, and the like. One survey participant addressed both staff and training concerns as follows: "The inclusion model is difficult since we are not trained special education teachers and do not have enough support staff to help with inclusion..."

Combining the qualitative data, various themes and subthemes emerged regarding the implementation of EBPs for social skills. The themes were derived from codes. The following Table 5 presented the top seven codes.

Table 5. Top 7 Codes from All Qualitative Sources Related to Barriers by Frequency of Responses

\begin{tabular}{lc}
\hline Code & $\begin{array}{c}\text { Frequency of } \\
\text { Responses }\end{array}$ \\
\hline Lack of Training in EBPs & 33 \\
Lack of Time & 24 \\
Lack of Support Staff to Meet Social Needs and & 17 \\
Implement EBPS & 13 \\
Lack of Staff "Buy In" and/or Motivation of teachers & 12 \\
Lack of Curriculum/Materials (need for materials) & 12 \\
Lack of Support for EBPS by Administrators/District & 12 \\
Prioritization of needs & \\
\hline
\end{tabular}

The following Figure 1 presents an illustration of the themes and subthemes obtained from the merging of quantitative and qualitative data.

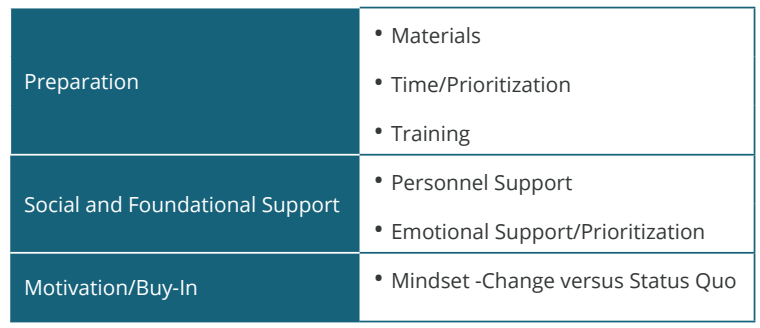

Figure 1. Themes and Subthemes from Combined Qualitative and Quantitative Sources

Regarding the Implementation of EBPs for Social Skills for Students with Autism

Themes and subthemes revealed in this study were determined from nodes/codes based on a variety of different factors, including: the frequency of the code, the intensity of the various comments, member checking, and 
the connection of the codes to multiple methods of data triangulation (interviews, the open-ended survey question, surveys, and field notes). The three primary themes that emerged from this study regarding the implementation of EBPs for social skills in inclusive settings: (1) there is a need for preparation; (2) there is a need for support (both physical and emotional), and (3) there is a need for motivation/staff buy-in. Under the preparation theme, subthemes of training, materials, prioritization, and time emerged. Under the support theme, the need for extra staff support as well as the need for emotional support surfaced. The subtheme of change versus status quo/mind-set fell under the broader theme of motivation.

Subtheme: Mind-set-Change versus Status Quo. Throughout the study, several staff members expressed concern that the implementation of EBPs for social skills might be challenging due to staff's inclination to maintain the status quo. Staff members noted that many district staff were still having difficulty embracing the district's current inclusion plan. A focus group member referenced inclusion colleagues when she stated, “They (inclusion general education staff) don't necessary want interventions; they want the child to be in a different class setting." Another educator succinctly indicated, "The mindset of some staff members is a barrier to the implementation of EBPs for social skills." Echoing this sentiment, a focus group staff member exclaimed, "buy-in is huge!" Another staff emphasized that not only teacher buyin was critical, but administrator buy-in was key, "If it's (social skills training) going to be utilized in a school, it's really necessary to get the principal to buy-in to the social skill training." Some Focus Group Members shared that they thought that the fact that the principal at their site supported inclusion as well as EBPs such as video modeling, made a huge difference in the entire staff's approach to inclusion and EBPs.

Another inclusive staff member noted that she had witnessed a "lack of willingness of general educators to want to be trained and to implement programs." This sentiment was reverberated during focus groups when one of the district's behaviour staff elaborated, "I've tried to train, but sometimes, they don't want it. All they want is a body." Several staff members voiced similar thoughts - that rather than want to learn and implement these strategies on their own, some inclusion staff members want someone else to be responsible for the student and for carrying out any necessary recommendations that might enhance the student's social skills. However, the attitudes expressed by those staff members related to inclusion participating in the focus/training groups, as well as the attitudes clearly expressed by two general education teachers who consented to have their students with HFA participate in a peer mediated intervention administered by the primary researcher, was in direct contrast to the negativity that other members referenced. Those staff members reported that they were "eager to learn" and they wanted to know the "best ways" to provide supports to the students in HFA. They expressed a strong desire to make the student feel wanted and accepted as well as ways to improve their social skills and reduce problem behaviours. A general education teacher exclaimed, "I just want him (student with HFA) to feel that he belongs....I want to know how to help him."

Subtheme: Training. During the study, inclusion staff and stakeholders lamented that the amount, quality, and type of training they had received to meet the social and academic needs of students with HFA in inclusion was insufficient, specifically, training regarding EBPs for social skills interventions was very lacking. While several behaviour staff members in the Focus Group reported feeling comfortable with many types of EBPs for social skills such as peer mediated interventions (PMI) and pivotal response training (PRT), other focus group members remarked, "I've never even heard of those interventions before!" Another general educator claimed,
"This intervention (regarding the social skills interventions for her student with HFA being implemented by the primary researcher) is so important... I'm not trained to do this!" Yet another regular education inclusion teacher lamented, "I didn't study special education. I'm at a loss!" On the barriers to implementation survey's open-ended question, one of the inclusion staff members wrote:

I honestly feel that the biggest barrier is the lack of training for teachers or support from the district. The inclusion model is difficult since we are not trained special education teachers and do not have enough support staff to help with inclusion kids. Our RSP (resource specialist - i.e. education specialist) teacher is wonderful, but she can only do so much to help.

As one focus group member stated simply, "You can't do something if you don't know how to do it."

Other participants noted that school staff aren't the only ones that need training. The parent advocate lamented, "Nearly all of my training has been self- taught! - We parents need training, too!" Staff also added, "Don't forget the classroom peers! Many peers don't understand the child with autism... many don't even know what autism means!" Staff elaborated that they had seen typical peer responses to their peers with autism in inclusive settings range widely from nurturing and caring to afraid and bewildered.

Subtheme: Materials. The subtheme of materials encompasses a wide range of actual products, curriculums, training tools, reinforcement incentives (i.e. rewards for the demonstration of pro-social skills), and access to online resources that allow for materials to be utilized to facilitate the implementation of EBPs in social skills for students with HFA in school settings. During focus groups, when the primary researcher introduced two well-known structured social skills group training (SSGT) interventions (Skills-Streaming and Stop \& Think), many group members remarked that they never knew that those materials were available in the district. When the staff of one elementary school shared that their principal had purchased a video modelling (VM) online program for all inclusion staff at the school to utilize, other staff members immediately expressed a desire to have access to that program (or similar programs as well). One member remarked, "All of us should have access to a program like that!" In absence of an online software program, focus group members noted that to effectively engage in VM, "At the very least, one needs a phone, computer, or IPAD." One focus group member echoed, "Video modeling would be great. But if you don't have a way to do it, you can't implement it!" Many staff members reported that they were unfamiliar with appropriate online resources that could ease the facilitation of EBPs for social skills, and when provided with several of those resources, a staff member noted, "This is very practical and helpful!

Visual supports and materials are often required for such EBPs for social skills as positive behaviour interventions (PBI) or social narratives (SN). However, many inclusion staff reported that they lacked access to these supports, were not familiar with creating them, and/or lacked access to materials needed to create them. Several staff members indicated that educators spend their own money on basic student resources such as pens, paper, stickers, laminator sheets, and glue. The district's autism behaviour staff reported that they purchased their own laminator, laminator sheets, cardstock, and manipulatives for the students that they serve for the district out of their own pocket. One special education teacher exclaimed "I realized a while ago that if I needed a visual support for a student with autism, I'd have to make it myself!"

Subtheme: Time/Prioritization. To implement EBPs for social skills in inclusion settings more regularly, staff reported that time was a critical element. Time encompasses planning time, time to implement the intervention, collaboration time with other staff, training time, transition time, and time to devote to data collection and/or other methods of assess- 
ing the intervention. One focus/training group member noted, "It takes time ... to prepare the materials and even to think about what you are going to do." Another focus group member wondered aloud, "And will the teacher give us the time to do it with them (the students)?" A general education teacher explained, "I have 30 students in my class and I just don't have the time to meet all their needs by myself." Another member exclaimed that in order to implement EBPs for social skills, "I would need planning time. A plan that is supported from the top." As discussions evolved, prioritization of demands appeared to blend with the subtheme of time. A staff member remarked, "Most of the training that I ever received focused on academics, very little of my training focused on social skills." One participant noted that social skills and behaviour had suddenly become a major concern for early elementary students, while in the past, these concerns were not as evident until later elementary years. That participant elaborated: "I think principals are starting to realize how much of their time now is being spent on behaviours - time and energy... going into kindergarten, 1st and 2nd grade students with challenging behaviours..." Another group member affirmed this statement exclaiming, "Yes, it's time for us to shift our energy.' A regular education staff member elaborated, "My day is so full already with other things that I need to fit in, I don't know when or how I could fit in anything else." Another participant emphasized the need for administrator buy-in as well as for administrators to prioritize social skills, "If it's (social skills' training) going to be utilized in a school, it's really necessary to get the principal to buy-in to the social skill training and, you know, previously their focus has been on test scores, and the focus has been more academic."

Subtheme: Personnel Support. To implement EBPs for social skills interventions for students with HFA, the subtheme of support strongly resonated with study participants. Inclusion staff noted that the social, behaviour, and academic challenges exhibited by students with autism in inclusion settings can be "severe" and/or "overwhelming." A general educator articulated, "If inclusion is to be part of our academic program then we need to have the support staff. We need to have well trained support staff to work with these students." That particular general education teacher elaborated the need for two types of support staff: in classroom trained instructional assistants, and collaborated support, such as trained professionals who could guide and support the program as well on a more frequent and regular basis. One general education teacher expressed, "We have these inclusion students in our classrooms now. And, sadly, the support is very limited that's being provided for us...And when you look at the minutes, most of the time you're in that classroom alone with the 30 students or relying on parent volunteers, which that's not their job. And they shouldn't be doing that." Another regular education teacher echoed the same sentiment. "There is a need for support- it would be helpful to have an aide who can support the specific student or assist the rest of the class while I support the student." Regarding the need for additional instructional assistants, focus group members cautioned that having another adult body in the classroom is not always helpful unless that person has been trained. As one staff member exclaimed, "Sometimes the wrong help can do more damage than good!" Simply put, another stated, "I need help! I have so many kids with so many needs!"

Subtheme: Emotional Support. In addition to personnel support, study members expressed and/or alluded to the need for increased emotional support to meet the social needs of students with HFA in inclusive settings via EBPs. Inclusion staff noted that students with autism occasionally present with disruptive and/or aggressive behaviours and that such behaviours can extract an emotional toll on an educator. Sometimes staff need to vent, debrief, and/or relax in a safe, supportive environment with a caring, non-judgmental co-worker. "It would be nice to have someone to talk to more often who understands what I'm going through." Staff acknowledged feeling "very stressed" at times. Some of the inclusion staff members, especially the general education teachers, involved in the study expressed a sense of being overwhelmed by the demands of their job as inclusion educators and feeling a sense of isolation. As one educator expressed, "There is a need for more collaboration among professionals...if there was more collaboration, I wouldn't feel so alone in this."

Some inclusion staff members expressed frustration with district administrators, stating, "I don't think they [administrators] really are listening to us when we tell them what we need." A focus group member speculated, "I don't even think that they really understand what is going on out there." Focus group members expressed a dis-connect between administrators making decisions regarding inclusive practices and the staff called upon to implement those practices. Other staff members shared that they experienced a lack of appreciation from administrators for the work that they do as inclusion educators. As one staff noted, "It would be nice if they recognized all that we do!" Another educator mentioned that the administrator would have to consider social skills as a priority for the teacher to be able to spend time addressing social skills in her daily schedule. A lack of emotional support, however, was not an area of concern expressed by all study participants. Staff from one elementary school reported feeling very supported by their principal and the staff at their school site. As one staff member from that school exclaimed, "My school has been very willing to try to make inclusion work!"

The need for emotional support was identified not only for inclusion staff, but for the students with HFA and their typical peer counterparts as well. Staff expressed a concern that the students with HFA in inclusion classes struggle to "find their place" in mainstream classes and do not always feel welcomed. The parent in the focus/training groups shared, "Focusing on social skills would reduce the students' anxiety levels, as well. And help them feel more included and comfortable in class." Other staff touched upon the needs of the typical peers in inclusion classes, "The typical students in these classes need support and training just as much as the students with HFA." Staff expressed a concern that the level of disruptive behaviours that typical students are exposed to in inclusion classes can have a negative impact on their emotional well- being. Currently, few, if any, strategies or plans are in place in place in inclusive settings to address this experience and to provide the typical peers with the additional supports that they need for inclusion settings to be as beneficial as possible to all.

\section{Discussion/Implications for Practice}

This study provided an exploration of the barriers to the implementation of social skills interventions for students with HFA in inclusive settings. By successfully identifying roadblocks to the implementation of EBPs for social skills interventions in inclusive settings, strategies can be identified to address those roadblocks to facilitate the development of a sustainable district plan routinely and effectively implement EBPs. Based on this mixed-methods design study, the top six barriers to the successful implementation of social skills as identified by early elementary inclusion staff include: (a) training, (b) time, (c) support, (d) prioritization of demands, (e) materials, and ( $f$ ) staff mindset. These findings are consistent with previous studies identifying barriers to the implementation of EBPs for autism (Cook \& Odom, 2013; Foster, 2014; Miller, 2017; Owens et al., 2014). Occasionally, interventions fail due to lack 
of stakeholder buy in or consideration (Locke et al., 2015) therefore, listening to the voices of inclusion educators and stakeholders may optimize the success of the implementation of EBPs. This study is unique in the personal approach to the problem of bridging the gap between research and practice, the direct involvement of stakeholders, the utilization of mixed methods, and the focus on inclusive settings. Ostmeyer and Scarpa (2012) took a similar approach utilizing PAR to identifying the barriers impeding EBPS for students with autism. If school districts and/or other educational environments took a similar approach to the research/practice gap (listening to the voices of their inclusion stakeholders and involving them in the plan to bridge the gap), then perhaps more settings would be able to successfully implement EBPs for social skills for students with autism.

Preparation emerged as a major theme presented across the various data collection methods utilized in this study. The lack of preparation on many levels was frequently cited as a barrier to the implementation of EBPs for social skills, while the provision of preparation was viewed as a way to stimulate districts to implement EBPs for social skills. Many inclusion staff members expressed the sentiment that they were ill equipped to provide EBPs for social skills to students with HFA in inclusive settings for a variety of reasons. Training focusing specifically on meeting the needs of students with autism are limited in regular teacher credential programs (Holdheide \& Reschly, 2008) which results in educators being unprepared to adequately address the needs of students with autism (Lauderdale-Littin, \& Brennan, 2018; Suhrheinrich, 2011). Teaching children with autism presents with challenges (Lindsay et al., 2013; Zager, Wehmeyer, \& Simpson, 2012). As more students with autism are included in mainstream classes, the need to prepare all educators to address the needs of students with autism is imperative (Alexander, Ayres, \& Smith, 2015; Loiacono \& Valenti, 2010; Marder \& Fraser, 2012; Marder \& DeBettencourt, 2015). Lindsay et al., (2013) noted, that teachers feel unprepared to support students with autism "socially, academically, and behaviourally" (p. 348). Marder and Fraser (2012), purport:

Teacher preparation programs need to ensure that future teachers are provided with the tools to accurately evaluate research to identify evidence-based practice; how to implement that practice in their daily teaching strategies, and how to keep current on the emerging research studies that evaluate evidence-based practices for teaching students with autism (p. 5).

This study highlights the need for training on EBPs for social skills for students with autism to be included in educator credentialing programs for both regular education and special education teachers. The findings of this study reaffirmed earlier studies that even educator specialists lack awareness of EBPs for autism (Combes et al., 2016; Klebanoff, 2018). It is strongly recommended that training on EBPs be incorporated in programs for regular (AKA general) educators, special education teachers, service professionals and support staff. On individual school sites, training on EBPs could be extended beyond immediate inclusion staff, to include other staff on campus, such as noon supervisors and service providers, as well as the parents of students with HFA, to enhance generalization of social skill acquisition. Recent implementation science research is calling for trainings which involve field experience (Lauderdale-Litten \& Brennan, 2018). A varied team of district experts could act as the "demo group" for district inclusion staff, and field training could be incorporated into those training modules. The "demo group" could assure that district inclusion have also have access to resources, websites, and materials for EBPs for social skills. To address the lack of materials, school site teams could "share" equipment among schools and/or if certain programs are purchased in volume, the cost would be more economical for the district. Furthermore, districts may research implementing programs and curriculums that are evidence-based, but more cost-ef- fective. This approach is akin to the best fit model emphasized by Forman, Olin, Hoagwood, Crowe, and Saka (2009) that matches the needs of the district or site to a an EBP that works for them.

The second theme manifested throughout the qualitative data was social and foundational support. The need for support reverberated throughout the study. Lack of sufficient support staff has been documented as a barrier to the implementation of EBPs for social skills (Able et al., 2015; Locke et al., 2015) Lack of emotional support has been alluded to in prior studies, such as the reference to a school's climate or culture impacting the implementation of EBPs or to feelings of burnout reported by staff working with students with ASD (Corona, Christodulu, \& Rinaldi, 2017; Woodcock \& Woolfson, 2019). In addition, inclusion has been linked to higher rates of teacher stress and burnout, particularly for those regular education teachers who have not had the benefit of the training that they special education counterparts have experienced (Boujut et al., 2016; Lindsay et al., 2013). To address the need for support, school district and site wide inclusion teams encompassing a range of district service providers could be created. For example, each school site team could meet monthly and at least twice a year, they could meet to address ways in which the team could ensure that each student with HFA on their campus receives EBPs for social skills in a structured manner. Districts may also consider increasing staff support (physical support as in increased staff and emotional support) to implement the EBPs strategies so staff would not feel so isolated and they would feel better equipped to meet the demands of inclusive settings.

Another effective method of enhancing social skills of students with autism is to teach the typical child about autism and ways that they could assist their peers with autism (Koegel, Matos-Freden, Lang, \& Koegel, 2012). Districts may consider placing more emphasis on teaching typical peers about autism and ways that they may support their peer counterparts with autism in inclusion settings. Research indicates that typical peers are not being utilized to assist their peers effectively (Koegel, Vernon, Koegel, Koegel, \& Paullin, 2012) and this study affirmed that many typical peers have not been trained to support or understand their peers with autism. Furthermore, typical peers might require their own support (i.e. training and/or counseling supports) for inclusion settings to be as successful as possible for them, as well as their counterparts with HFA.

The final primary theme evident throughout the study was that of "buy-in" - conquering the status quo mindset and motivating staff to see the relevance and importance of EBPs for social skills to be implemented in inclusive settings. To enhance inclusion and change teacher's perceptions of inclusion, the following supports are recommended: (a) additional training regarding autism and behaviour for all teachers, (b) support and/or peer mentoring, (c) additional supports and resources (including additional involvement from parents, administrators, and other school professionals); and (d) adopting a proactive versus reactive mentality (Lindsay et al., 2013; Majoko, 2015). Researchers have discovered the staff buy-in to a practice or curriculum can be the critical factor that distinguishes high implementers from low implementers (Lieber et al., 2009). Motivation or buy-in is a key element of the Fogg Behaviour Model (Fogg, 2009). For systemic change to occur, the FBM (Fogg, 2009) accentuates that there must be motivation or investment on behalf of the individual or group. Fogg (2018) described motivation and ability as compensatory in that if one's motivation is high to engage in a behaviour, then one's ability could be lower; conversely, if one's ability is high, then motivation could potentially be lower to effect a behavioural change. Lewin, one of the early originators of change theory, envisioned change as an alteration of forces maintaining stability (Cummings, Worley \& Cummings, 2001). Specifically, Lewin noted that a particu- 
lar set of behaviours at any moment in time is the result of two groups of forces: those striving to maintain the status quo and those pushing for change (Lewin, as cited in Cummings et al., 2001). Therefore, to facilitate implementation of EBPs, districts should seek to involve their stakeholders and increase collaboration between administrators, staff, parent, and students. Research supports a team/collaborative approach to spur the successful implementation of EBPs for autism (Donaldson \& Stahmer; 2014; Odom et al., 2014). Since many staff do not feel ready to implement desired systemic changes, leaders are encouraged to communicate with staff to develop a deeper understanding of their concerns (Odom et al., 2014). As prior noted, research suggests that some students with HFA can sense a teacher's attitudes toward them and that any teacher-student conflict can contribute to feelings of rejection or loneliness within inclusive settings (Mazurek, Kanne, \& Wodka, 2013; Zeedyk, Cohen, Eisenhower, \& Blacher, 2016). If broad inclusion staff buy-in were achieved, students with special needs in inclusive settings would likely feel more welcome and, thus, less anxious, in inclusive settings.

\section{Limitations}

This study focused on students with high functioning autism as opposed to the broader autism spectrum, therefore, generalizations of this study to other populations with autism may be limited. Another study limitation was the lack of greater role diversity in the focus group (for example, only one parent of a student with HFA was able to participate and no administrator was able to attend). Furthermore, while several regular education inclusion teachers completed the survey, and two of the regular education teachers also participated in semi-structured interviews, no regular education teachers were able to participate in the actual focus groups. It is also possible that the opinions expressed by the focus group participants did not reflect the opinions of other staff in the district. Lastly, researcher bias is a concern in research especially due to the nature of PAR in which the lines of researcher and participant and facilitator may be blurred. Member checking and self-monitoring systems were employed to limit bias.

\section{Conclusion}

Over the past two decades in the United States, there has been an impetus for more students with disabilities to be included in mainstream education inclusive settings. Despite benefits for some students, inclusion brings challenges for educators, students with autism, typical peers, and parents of students in inclusive settings. For students with HFA to be as successful as possible in inclusive settings, EBPs interventions for social skills should be regularly implemented and imbedded within district inclusion plans. Currently, however, there is a gap between research and practice - most inclusion staff members remain largely unaware of many evidence-based practices for social skills for students with autism and/or do not utilize EBPs for social skills. To successfully implement EBPs for social skills in inclusive settings, inclusion stakeholders require preparation, support (personnel support and emotional support), and an open mind-set.

\section{References}

Able, H., Sreckovic, M. A., Schultz, T. R., Garwood, J. D., \& Sherman, J. (2015). Views from the trenches: Teacher and student supports needed for full inclusion of students with ASD. Teacher Education and Special Education, 38, 44-57. doi: 10.1177/0888406414558096

Alexander, J. L., Ayres, K. M., \& Smith, K. A. (2015). Training teachers in evidence-based practice for individu- als with autism spectrum disorder. A review of the literature. Teacher Education and Special Education: The Journal of the Teacher Education Division of the Council for Exceptional Children, 38(1), 13-27.

Åsberg, J., Kopp, S., Berg-Kelly, K., \& Gillberg, C. (2010). Reading comprehension, word decoding and spelling in girls with autism spectrum disorders (ASD) or attention-deficit/hyperactivity disorder (AD/HD): Performance and predictors. International Journal of Language \& Communication Disorders, 45(1), 61-71.

Balfanz, R., Byrnes, V., \& Fox, J. (2015). Sent home and put off track: The antecedents, disproportionalities, and consequences of being suspended in the 9th grade. In D. J. Losen (Ed.), Closing the school discipline gap: Equitable remedies for excessive exclusion. New York, NY: Teachers College Press.

Bauminger, N., \& Kasari, C. (2000). Loneliness and friendship in high-functioning children with autism. Child Development, 71, 447-456.

Boujut, E., Dean, A., Grouselle, A., \& Cappe, E. (2016). Comparative study of teachers in regular schools and teachers in specialized schools in France, working with students with an autism spectrum disorder: Stress, social support, coping strategies and burnout. Journal of Autism and Developmental Disorders, 46(9), 2874-2889. doi:10.1007/s10803-016-2833-2

Brown, J. A., \& McIntosh, K. (2012). Training, inclusion, and behaviour: Effect on student-teacher and student-SEA relationships for autistic students with autism spectrum disorders. Exceptionality Education International, 22(2), 77-88.

Calder, L., Hill, V., \& Pellicano, E. (2013). 'Sometimes I want to play by myself': Understanding what friendship means to children with autism in mainstream primary schools. Autism,7(3), 296-316.

Camargo, S. P., Rispoli, M., Ganz, J., Hong, E. R., Davis, H., \& Mason, R. (2014). A review of the quality of behaviourally-based intervention research to improve social interaction skills of children with ASD in inclusive settings. Journal of Autism and Developmental Disorders, 44, 2096-2116. doi:10.1007/s10803014-2060-7

Chamberlain, B., Kasari, C., \& Rotheram-Fuller, E. (2007). Involvement or isolation? The social networks of children with autism in regular classrooms. Autism Developmental Disorders,37(2), 230-42.

Chiang, H., \& Gau, S. S. (2016). Comorbid psychiatric conditions as mediators to predict later social adjustment in youths with autism spectrum disorder. Journal of Child Psychology \& Psychiatry, 57(1), 103111. doi:10.1111/jcpp.12450

Cidav, Z., Marcus, S. C., \& Mandell, D. S. (2012). Implications of childhood autism for parental employment and earnings. Pediatrics, 129(4), 617-623. doi:10.1542/ peds.2011-2700

Cole, C., \& McCurdy, E. (2014). Use of a peer support intervention for promoting academic engagement of autistic students with autism in general education settings. Journal of Autism \& Developmental Disorders, 44(4), 883-893. doi:10.1007/s10803-013-1941 
Combes, B. H., Chang, M., Austin, J. E., \& Hayes, D. (2016). The use of evidenced-based practices in the provision of social skills training for students with autism spectrum disorder among school psychologists. Psychology in the Schools, 53(5), 548-563. doi:10.1002/ pits. 21923

Cook, A., Ogden, J., \& Winstone, N. (2017). Friendship motivations, challenges and the role of masking for girls with autism in contrasting school settings. European Journal of Special Needs Education, 32(4), 1-15. doi:10. 1080/08856257.2017.1312797

Cook, B., \& Odom, S. (2013). Evidence-based practices and implementation science in special education. Exceptional Children,79, 135-144.

Corona, L. L., Christodulu, K. V., \& Rinaldi, M. L. (2017). Investigation of school professionals' self-efficacy for working with students with ASD: Impact of prior experience, knowledge, and training. Journal of Positive Behaviour Interventions, 19(2), 90-101.

Creswell, J. W. (2012). Educational research: Planning, conducting, and evaluating quantitative and qualitative research (4th ed.). Boston, MA: Pearson.

Cummings, T. G., Worley, C. G., \& Cummings, T. G. (2001). Essentials of Organization development and change. Cincinnati, OH: South-Western College Pub.

Davidson, M., \& Weismer, S. (2014). Characterization and prediction of early reading abilities in children on the autism Spectrum. Journal of Autism \& Developmental Disorders, 44(4), 828-845. doi:10.1007/s10803-0131936-2

Dominick, K., Davis, N., Lainhart, J., Tager-Flusberg, H., \& Folstein, S. (2007). Atypical behaviours in children with autism and children with a history of language impairment. Reserved Developmental Disability, 28(2):145-62.

Domitrovich, C., Bradshaw, C., Poduska, J., Hoagwood, K., Buckley, J., Olin, S., ... lalongo, N. (2008). Maximizing the implementation quality of evidence-based preventive interventions in schools: A conceptual framework. Advances in School Mental Health, 1, 6-28. doi: 10.1080/1754730X.2008.9715730

Donaldson, A. L., \& Stahmer, A. C. (2014). Team collaboration: The use of behaviour principles for serving students with ASD. Language, Speech, and Hearing Services in Schools, 45, 261-276.

Eikeseth, S., Klintwall, L., Jahr, E., \& Karlsson, P. (2012). Outcome for children with autism receiving early and intensive behavioural intervention in mainstream preschool and kindergarten settings. Research in $\mathrm{Au}$ tism Spectrum Disorders, 6(2), 829-835. doi:10.1016/j. rasd.2011.09.002

Eisenhower, A., Baker, B., \& Blacher, J. (2005). Preschool children with intellectual disability; syndrome specificity, behaviour problems, and maternal well-being. Journal of Intellectual Disability Research. 49, 657-71.

Fink, E., Begeer, S., Peterson, C. C., Slaughter, V., \& Rosnay, M. D. (2014). Friendlessness and theory of mind: A prospective longitudinal study. British Journal of Developmental Psychology, 33(1), 1-17. doi:10.1111/ bjdp.12060.

Fogg, B. J. (2009). A behaviour model for persuasive design. Proceedings of the 4 th International Conference on Per- suasive Technology, April 26-29, 2009, Claremont, CA.

Fogg, B. J. (2018). What causes behaviour change? BJ Fogg's Behaviour Model. Retrieved from https://www.behaviourmodel.org/

Forman, S. G., Olin, S. S., Hoagwood, K., Crowe, M., \& Saka, N. (2009). Evidence-based interventions in schools: Developers' views of implementation barriers and facilitators. School Mental Health, 1(1),26-36

Foster, R. (2014). Barriers and enabler to evidence-based practices. Kairaranga, 15(1), 50-58.

Fox, L., Hemmeter, M. L., Snyder, P., Binder, D. P., \& Clarke, S. (2011). Coaching early childhood special educators to implement a comprehensive model for promoting young children's social competence. Topics in Early Childhood Special Education, 31, 178-192.

Fulton, E., Eapen, V., Črnčec, R., Walter, A., \& Rogers, S. (2014). Reducing maladaptive behaviours in preschool-aged children with autism spectrum disorder using the Early Start Denver Model. Frontiers in Pediatrics, 2, 40, 1-10. http://doi.org/10.3389/fped.2014.00040

Gerhardt, P. F. \& Crimmins, D. (Eds.) (2013). Social skills and adaptive behaviours in learners with autism spectrum disorders. Baltimore: Paul H. Brookes Publishing Co.

Grindle, C. F., Hastings, R. P., Saville, M., Hughes, J. C., Kovshoff, H., \& Huxley, K. (2009). Integrating evidence-based behavioural teaching methods into education for children with autism. Educational and Child Psychology, 26, 65-81. doi:10.1007/s10803-0111234-910.1007/s10803-011-1234-9

Goodall, C. (2015). How do we create ASD-friendly schools? A dilemma of placement. Support for Learning, 30, 4, 305-326. doi:10.1111/1467-9604.12104

Grove, R., Baillie, A., Allison, C., Baron-Cohen, S., \& Hoekstra, R. A. (2014). The latent structure of cognitive and emotional empathy in individuals with autism, first-degree relatives and typical individuals. Molecular Autism, 5(1), 42. doi:10.1186/2040-2392-5-42

Harrell, M.C., Bradley, M. (2009). Data collection methods: semi-structured interviews and focus groups. Santa Monica, CA: RAND Corporation

Hansen, S., Blakely, A., Dolata, J., Raulston, T., \& Machalicek, W. (2014). Children with autism in the inclusive preschool classroom: A systematic review of single-subject design interventions on social communication skills. Review Journal of utism Developmental Disorders 1, 192-206. doi:10.1007/s40489-014-0020-y

Hess, K. L., Morrier, M. J., Heflin, L. J., \& Ivey, M. L. (2008). Autism treatment survey: Services received by children with autism spectrum disorders in public school classrooms. Journal of Autism and Developmental Disorders, 38, 961-971.

Hicks, T. B., Shahidullah, J. D., Carlson, J. S., \& Palejwala, M. H. (2014). Nationally certified school psychologists' use and reported barriers to using evidence-based interventions in schools: The influence of graduate program training and education. School Psychology Quarterly, 29(4), 469-487. doi:10.1037/spq0000059

Hillier, A. J., Fish, T., Siegel, J. H., \& Beversdorf, D. Q. (2011). Social and vocational skills training reduces self-report- 
ed anxiety and depression among young adults on the autism spectrum. Journal of Developmental and Physical Disabilities, 23, 267 - 276. doi:10.1007/ s10882-011-9226-4

Hilton, A., \& Liberty, K. (1992). The challenge of ensuring educational gains for students with severe disabilities who are placed in more integrated settings. Education and Training of the Mentally Retarded, 27, 167-175.

Holbrook, A., Krosnick, J., \& Pfent A. (2010). The causes and consequences of response rates in surveys by the news media and government contractor survey research firms. In: Lepkowski JM, Tucker NC, Brick JM, De Leeuw ED, Japec L, Lavrakas PJ, et al, (Eds.). Advances in Telephone Survey Methodology. New York (NY): Wiley.

Holdheide, L. R., \& Reschly, D. J. (2008). Teacher preparation to deliver inclusive services to students with disabilities: TQ Connection Issue Paper. National Comprehensive Center for Teacher Quality, 1-28.

Humphrey, N., \& Symes, W. (2013). Inclusive education for pupils with autistic spectrum disorders in secondary mainstream schools: Teacher attitudes, experience and knowledge. International Journal of Inclusive Education, 17(1), 32-46. doi:10.1080/1360 3116.2011 .580462

Jones, D., Greenberg, M., \& Cowley, M. (2015). Early social-emotional functioning and public health: The relationship between kindergarten social competence and future wellness. American Journal of Public Health, 105(11), pp. 2283-2290.

Jordan, R., Roberts, J., \& Hume, K. (2019). The SAGE Handbook of Autism and Education. Cambridge, MA: Sage

Kamps, D., Thiemann-Bourque, K., Heitzman-Powell, L., Schwartz, I., Rosenberg, N., Mason, R., \& Cox, S. (2015). A comprehensive peer network intervention to improve social communication of children with autism spectrum disorders: A randomized trial in kindergarten and first grade. Journal of Autism and Developmental Disorders, 45(6), 1809-1824. http://doi.org/10.1007/s10803-014-2340-2

Kasari, C., \& Smith, T. (2013). Interventions in schools for children with autism spectrum disorder: Methods and recommendations. Autism, 17, 254-267. [PubMed: 23592848].

Kasari, C., Locke, J., Gulsrud, A., \& Rotheram-Fuller, E. (2011). Social networks and friendships at school: Comparing children with and without ASD. Journal of Autism and Developmental Disorders, 41(5), 533544. doi:10.1007/s10803-010-1076-x

Kasari, C., Rotheram-Fuller, E., Locke, J., \& Gulsrud, A. (2012). Making the connection: Randomized controlled trial of social skills at school for children with autism spectrum disorders. Journal of Child Psychology and Psychiatry, and Allied Disciplines, 53(4), 431-439. doi :10.1111/j.1469-7610.2011.02493

Kemmis, S. (2016). Action research planner: Doing critical participatory action research. New York, NY: Springer.

Klebanoff, S. (2018). School psychologists' and counselors' perspectives on evidence-based practices for chil- dren with autism spectrum disorders. (Order No. ED590873). ProQuest LLC, Dissertation, University of California, Los Angeles. Retrieved from http:// gateway.proquest.com/openurl?url_ver=Z39.882004\&rft_val_fmt=info:ofi/fmt:kev:mtx:dissertation\&res_dat=xri:pqm\&rft_dat $=x r i: p q-$ diss:10936863.

Koegel, L., Matos-Freden, R., Lang, R., \& Koegel, R. (2012a). Interventions for children with autism in inclusive school settings. Cognitive and Behavioural Practice, $19,401-412$

Koegel, L., Robinson, S., \& Koegel, R. (2009). Empirically supported intervention practices for autism spectrum disorders in school and community settings: Issues and practices. In W. Sailor, G. Dunlap, G. Sugai, \& R. Horner (Eds.), Handbook of positive behaviour support (pp. 149-176). New York, NY: Springer.

Koegel, L., Vernon, T., Koegel, R., Koegel, B., \& Paullin, A. (2012b). Improving social engagement and initiations between children with autism spectrum disorder and their peers in inclusive settings. Journal of Positive Behaviour Interventions, 14(4), 220-227. doi:10.1177/1098300712437042

Lauderdale-Littin, S., \& Brennan, M. (2018). Evidence-Based Practices in The Public School: The Role of Preservice Teacher Training. International Electronic Journal of Elementary Education, 10(3), 369-375. https://doi-org.nnu.idm.oclc.org/10.26822/iejee.2018336195

Lauderdale-Litten, S., Howell, E., \& Blacher, J. (2013). Educational placement for children with autism spectrum disorders in public and non-public school settings: The impact of social skills and behaviour problems. Education and Training in Autism and Developmental Disabilities, 48(4), $469-478$.

Lieber, J., Butera, G., Hanson, M., Palmer, S., Horn, E., Czaja, C., ... Odom, S. (2009). Factors that influence the implementation of a new preschool curriculum. Early Education \& Development, 20, 456-481. doi. org/10.1080/10409280802506166

Lindsay, S., Proulx, M., Thomson, N., \& Scott, H. (2013). Educators' challenges of children with autism spectrum disorder in mainstream classrooms. International Journal of Disability, Development and Education, 60(4), 347-362. doi:10.1080/103491 2x.2013.846470

Locke, J., Beidas, R. S., Marcus, S., Stahmer, A., Aarons, G. A., Lyon, A. R., . . . Mandell, D. S. (2016). A mixed methods study of individual and organizational factors that affect implementation of interventions for children with autism in public schools. Implementation Science, 11(135). doi:10.1186/s13012016-0501-8

Locke, J., Olsen, A., Wideman, R., Downey, M. M., Kretzmann, M., Kasari, C., \& Mandell, D. S. (2015). A tangled web: The challenges of implementing an evidence-based social engagement intervention for children with autism in urban public-school settings. Behaviour Therapy, 46(1), 54-67. doi:10.1016/j.beth.2014.05.001

Loiacono, V., \& Valenti, V. (2010). General education teachers need to be prepared to co-teacher the increasing number of children with autism in inclusive 
settings. International Journal of Special Education, 25, 24-32.

Longtin, S. E. (2014). Using the college infrastructure to support students on the autism spectrum. Journal of Postsecondary Education and Disability, 27(1), 86-99.

Majoko, T. (2015). Inclusion of children with autism spectrum disorders: Listening and hearing to voices from the grassroots. Journal of Autism and Developmental Disorders, 46(4), 1429-1440. doi:10.1007/s10803-015-26851

Mallett, C. A. (2015). The school-to-prison pipeline: A critical review of the punitive paradigm shift. Child and Adolescent Social Work Journal, 33(1), 15-24. doi:10.1007/ s10560-015-

Marder, T., \& DeBettencourt, L. (2015). Teaching students with ASD using evidence-based practice. Why is training critical now? Teacher Education and Special Education, 38 (1) p. 5-12.

Marder, T., \& Fraser, D. (2012). Evidence-based practice for special educators teaching students with autism. New Horizons for Learning, 1-7.

Marshall, C., \& Rossman, G. (2016). Designing qualitative research (6th Edition). Los Angeles, CA: Sage.

Mazurek, M. O., Kanne, S. M., \& Wodka, E. L. (2013). Physical aggression in children and adolescents with autism spectrum disorders. Research in Autism Spectrum Disorders, 7(3), 455-465. doi:10.1016/j.rasd.2012.11.004

McGrew, J. H., Ruble, L. A., \& Smith, I. M. (2016). Autism spectrum disorder and evidencebased practice in psychology. Clinical Psychology: Science \& Practice, 23(3), 239-255. doi:10.1111/cpsp.12160

Miller, K. L. (2017). The use of evaluation in treatment programs for children with autism. Behaviour Analysis in Practice, 10(1), 35-44. http://doi.org/10.1007/s40617016-0130-3

Miller, M., Young, G. S., Hutman, T., Johnson, S., Schwichtenberg, A. J., \& Ozonoff, S. (2015). Early pragmatic language difficulties in siblings of children with autism: Implications for DSM-5 Social Communication Disorder? Journal of Child Psychology and Psychiatry, and Allied Disciplines, 56(7), 774-781. http://doi.org/10.1111/ jcpp.12342

Mordre, M., Groholt, B., Knudsen, A. K., Sponheim, E., Mykletun, A., \& Myhre, A. M. (2012). Is long-term prognosis for pervasive developmental disorder not otherwise specified different from prognosis for autistic disorder? Findings from a 30-year follow-up study. Journal of Autism and Developmental Disorders, 42(6), 920-928.

National Autism Center. (2015). Findings and conclusions: National standards project, phase 2. Randolph, MA: Author.

Northern Ireland Schools for Autism and Related Conditions Survey. (2015). In C. A. Goodall. Is it time for ASD specific schools? UTU News, Spring, pp. 16-17.

Odom, S., Buysse, V., \& Soukakou, E. (2012). Inclusion for young children with disabilities: A quarter century of research perspectives. Journal of Early Intervention, 33, 344-356.

Odom, S. L., Duda, M., Kucharczyk, S., Cox, A. W., \& Stable,
A. (2014). Applying an implementation science framework for adoption of a comprehensive program for students with ASD. Remedial and Special Education, 35, 123-132.

Øien, R., \& Eisemann, M. R. (2015). Brief report: Parent-reported problems related to communication, behaviour and interests in children with autistic disorder and their impact on quality of life. Journal of Autism and Developmental Disorders, 46(1), 328-331. doi:10.1007/ s10803-015-2577-4

Onwuegbuzie, A. J., \& Collins, K. M. T. (2007). A typology of mixed methods sampling designs in social science research. Qualitative Report, 12, 281-316. Retrieved from http://www.nova.edu/ssss/QR/QR12-2/onwuegbuzie2.pdfhttp://www.nova.edu/ssss/QR/QR122/onwuegbuzie2.pdf

Ostmeyer, K., \& Scarpa, A. (2012). Examining school-based social skills program needs and barriers for students with high-functioning autism spectrum disorders using participatory action research. psychology in the schools. Psychology in the Schools, Vol. 49 (10), 932941. doi:10.1002/pits.21646

Owens, J. S., Lyon, A. R., Brandt, N. E., Warner, C. M., Nadeem, E., Spiel, C., \& Wagner, M. (2014). Implementation science in school mental health: Key constructs in a developing research agenda. School Mental Health, $6(2), 99-111$.

Plavnick, J. B., Kaid, T., \& MacFarland, M. C. (2015). Effects of a school-based social skills training program for adolescents with autism spectrum disorder and intellectual disability, Journal of Autism and Developmental Disorders, 45(9), 2674-2690. doi:10.1007/s10803-0152434-5

Rabiner, D., Godwin, J., \& Kenneth, A. (2016). Predicting academic achievement and attainment: The contribution of early academic skills, attention difficulties, and social competence. School Psychology Review, 45 (2), 250 $-267$.

Ratcliffe, B., Wong, M., Dossetor, D., \& Hayes, S. (2015). The association between social skills and mental health in school-aged children with autism spectrum disorder, with and without intellectual disability, Journal of Autism and Developmental Disorders, 45, 2487-2496. doi:10.1007/s10803-015-2411-z

Ricketts, J., Jones, C. R., Happé, F., \& Charman, T. (2012). Reading comprehension in autism spectrum disorders: The role of oral language and social functioning. Journal of Autism and Developmental Disorders, 43(4), 807816. doi:10.1007/s10803-012-1619-4

Richardson, J. T. E. (2005). Instruments for obtaining student feedback: a review of the literature. Assessment \& Evaluation in Higher Education 30(4), 387-415.

Rodríguez-Medina, J., Martín-Antón, L. J., Carbonero, M. A., \& Ovejero, A. (2016). Peer-mediated intervention for the development of social interaction skills in high-functioning autism spectrum disorder: A pilot study, Frontiers in Psychology, 7, 1-11. doi:10.3389/ fpsyg.2016.01986

Sansosti, J. M., \& Sansosti, F. J. (2012). Inclusion for students with high-functioning autism spectrum disorders: Definitions and decision making. Psychology in the Schools, 49(10), 917-931. doi:10.1002/pits.21652 
Santomauro, D., Sheffield, J., \& Sofronoff, K. (2016). Investigations into emotion regulation difficulties among adolescents and young adults with autism spectrum disorder: A qualitative study. Journal of Intellectual \& Developmental Disability, 42(3), 275-284. doi:10.3109/13668250.2016.1236240

Shattuck, P. T., Narendorf, S. C., Cooper, B., Sterzing, P. R., Wagner, M., \& Taylor, J. L. (2012). Postsecondary education and employment among youth with an autism spectrum disorder. Pediatrics, 129(6), 10421049.

Scheeler, M. C., Budin, S., \& Markelz, A. M. (2016). The role of teacher preparation in promoting evidence-based practice in schools. Learning Disabilities: A Contemporary Journal, 14, 171-187.

Shea, N., Payne, E., \& Russo, N. (2018). Brief report: Social functioning predicts externalizing problem behaviours in autism spectrum disorder. Journal of $A u$ tism \& Developmental Disorders, 48(6), 2237-2242.

Silveira-Zaldivar, T. (2019). Utilizing participatory action research to implement evidence-based social skills interventions for elementary students with high functioning autism in inclusive classroom settings (Doctoral dissertation). Available from ProQuest Dissertations and Theses database. (UMI No. 13886434).

Smith, T. (2012). Making inclusion work for autistic students with autism with spectrum disorders: An evidence-based guide. New York, NY: Guildford Press.

Snyder, T.D., de Brey, C., and Dillow, S.A. (2016). Digest of Education Statistics 2015 (NCES 2016-014). National Center for Education Statistics, Institute of Education Sciences, U.S. Department of Education. Washington, DC.

Spencer, T. L. W. L. (2013). Exploring Asperger's syndrome, Schlossberg's transition theory and federally mandated transition planning: Seeking improvements (Doctoral Dissertation). Retrieved from ProQuest Dissertations \& Theses Full Text.

Sreckovic, M. A., Brunsting, N. C., \& Able, H. (2014). Victimization of autistic students with autism spectrum disorder: A review of prevalence and risk factors. Research in Autism Spectrum Disorders, 8(9), 11551172. doi:10.1016/j.rasd.2014.06.004

Stahmer, A., Reed, S., Lee, E., Reisinger, E. M., Connell, J. E., \& Mandell, D. S. (2015). Training teachers to use evidence-based practices for autism: Examining procedural implementation fidelity. Psychology in the Schools, 52(2), 181-195. doi:10.1002/pits.21815

Starr, E. M., Popovic, S., \& McCall, B. P. (2016). Supporting children with autism spectrum disorder at primary school: Are the promises of early intervention maintained? Current Developmental Disorders Reports, 3(1), 46-56. doi:10.1007/s40474-016-0069-7

Stringer, E. T. (2014). Action research. Los Angeles, CA: SAGE.

Strong, J. E. (2014). Preparing teachers of students with autism spectrum disorder: Evidence-based practices and teacher self-efficacy. (Order No. 3680113). Available from ProQuest Dissertations \& Theses Global. (1652923651). Retrieved from http://search.proquest.com.mutex.gmu.edu/ docview/1652923651?accountid=1454
Suhrheinrich J. (2011). Training teachers to use pivotal response training with children with autism; coaching as a critical component. Teacher Education and Special Education, 34(2),339-349.

Sullivan, M. (2009). Brilliantly disabled: fighting for special education services for students with Asperger's disorder. Children's Legal Rights Journal, 29(3), 4957.

Van Steensel, F., Deutschman, A., \& Bogels, S. (2012). Anxiety and quality of life: Clinically anxious children with and without autism spectrum disorders compared. Journal of Clinical Child \& Adolescent Psychology, 41(6), 731-738. doi:10.1080/15374416.2012.69 8725

Vismara, L., \& Rogers, S. (2010). Behavioural treatments in autism spectrum disorder: What do we know? Annual Review Clinical Psychology 6, 447-68.

Wolf, K., \& Kupchik, A. (2017). School suspensions and adverse experiences in adulthood. Justice Quarterly, 34(3), 407-420.

Woodcock, S., \& Woolfson, L. M. (2019). Are leaders leading the way with inclusion? Teachers' perceptions of systemic support and barriers towards inclusion. International Journal of Educational Research, 93, 232-242.

Wong, C., Odom, S. L., Hume, K., Cox, A. W., Fettig, A., Kucharczyk, S., ... Schultz, T. R. (2015). Evidence-based practices for children, youth, and young adults with autism spectrum disorder: A comprehensive review. Journal of Autism and Developmental Disorders, 45(7), p. 1951-1966.

Zager, D., Wehmeyer, M.L., \& Simpson, R.L. (2012). Educating students with autism spectrum disorders: Research-based principles and practices. New York, NY: Routledge.

Zeedyk, S., Cohen, S., Eisenhower, A., \& Blacher, J. (2016). Perceived social competence and loneliness among young children with ASD: Child, parent and teacher reports. Journal of Autism \& Developmental Disorders, 46(2), 436-449. doi:10.1007/s10803-0152575-6 